\title{
Probabilistic design of FRP strengthening of concrete structures
}

\author{
A. Carolin ${ }^{1} \&$ B. Täljsten ${ }^{2}$ \\ ${ }^{1}$ Luleå University of Technology, Sweden \\ ${ }^{2}$ Technical University of Denmark, Denmark
}

\begin{abstract}
For a long period of time CFRP plate bonding has been shown to be a competitive method for shear strengthening, both in regards to structural performance and economical aspects. A handful of models for design that include different strengthening aspects exist. Most proposals are derived from assumptions made for the design of new structures and are also based on a deterministic approach where in the best cases a safety factor is added. The use of probabilistic methods is extending and reliability of a designed structure is sometimes calculated. This paper presents how the reliability should be used in the design for strengthening an existing structure, which issues should be considered and also what safety one can expect from a structure strengthened in shear. Partial coefficients on material properties and loads are used to give a uniform treatment of the risk of failure. When partial coefficients are chosen, the reason for strengthening and the strengthening method may be considered to achieve an optimal strengthening with respect to structural safety and economy. The results from the analysis indicate design models for shear strengthening should be analytically determined with a transparent strategy for the uniform treatment of reliability aspects.
\end{abstract}

Keywords: shear strengthening, concrete structures, probabilistic design, frp, risk management, Monte Carlo simulations.

\section{Introduction}

All around us there are concrete structures intended for transportation or living. When such structures are built today, they are designed in accordance with codes that in many cases, EN [1], have their basis in probabilistic knowledge. Existing 
structures are sometimes evaluated because of increased demands or deterioration. When the capacities of existing structures are evaluated, it is quite common that probabilistic studies are used to ensure that the structure provides the desired safety. When a concrete structure is deemed to be insufficiently safe, Carolin [2] suggests that the alternatives are; strengthening, limitations of use, and replacement. Strengthening is very often the best alternative when keeping environment and economy in mind. For strengthening there exist several methods. Based on its wide acceptance and use, the strengthening method called "externally bonded fibre reinforced polymers" will be studied in the following. This method implies that reinforcement, most often carbon fibre, is added by adhesive bonding to an existing structure. The focus will be on strengthening for increased shear capacity since strengthening in flexure has previously been studied extensively. When it comes to the design of shear strengthening with externally bonded fibres, even though discussed, it is common to use the additional principle which gives the total shear bearing capacity, $V_{R}$, as the sum of the contribution from concrete, $V_{c}$, steel stirrups, $V_{s}$, and the strengthening system, $V_{f}$, as shown in eqn. (1) and presented in detail in Carolin and Täljsten [3].

$$
V_{R}=V_{c}+V_{s}+V_{f}
$$

Several alternatives to estimate $V_{c}$ for a beam have been suggested and eqn. (2) is one example where $b, z$, and $f_{v}$ are the beam width, beam height and the formal shear bearing strength of the concrete respectively.

$$
V_{c}=b z f_{v}
$$

One suggestion on how to determine $V_{s}$, by use of truss analogy is presented in eqn. (3).

$$
V_{s}=0.9 z A_{s} f_{y} / s,
$$

where $\mathrm{z}$ is internal lever arm in bending, $A_{s}$ is the cross-section of a steel stirrup, $f_{y}$ is the yield capacity of the steel and $s$ is the stirrup spacing. With the same assumption of a truss, $V_{f}$ has been suggested by Carolin and Täljsten [3] as presented in eqn. (4).

$$
V_{f}=\eta \varepsilon_{f} E_{f} t_{f} h \sin \beta \cos \theta / \sin \alpha,
$$

where $\eta$ is a reduction factor that considers linear elastic material, $\varepsilon_{f}$ is critical strain in fibres, $E_{f}$ is modulus of elasticity of fibres, $t_{f}$ is thickness of fibres, and $h$ is the height of the beam. The variables $\beta, \theta$ and $\alpha$ are angles considering principal strain, fibre direction and the difference between them. Whilst $V_{c}$ and $V_{s}$ have been calibrated with partial coefficients, a deterministic approach has so far been used for $V_{f}$. One can argue that eqn (4), and other similar equations, can easily be adopted to include partial coefficients. However, the calibration of coefficients is not that easily done and has only been undertaken to a limited extent, as for example by Monti and Santini [4]. When the design is 
deterministic, it is wise to add some safety, by use of an adjustment factor, to cover for uncertainties. Since distribution on the shear bearing capacity is not fully known, it is not possible to either add a specific safety or reduce the probability of failure to a specific level. Thus, the deterministic approach gives altering levels of safety for different structures and strengthening alternatives. With the uniform treatment of risks, the strengthening of structures could be achieved more efficiently with savings of costs and increased safety. This paper will give an introduction to the probabilistic design of strengthening and highlight some issues that need to be further studied and discussed. It is also time for calibration or assessment of partial coefficients to be used in the design of strengthening and one suggestion will be given.

\section{Probabilistic design}

By considering the distributions of loads and bearing capacity, a probabilistic approach can be used in design. There is always a probability of failure of a structural component, i.e. the load effect becomes larger than the bearing capacity. In a probabilistic approach, the probability of failure is either estimated afterwards or determined beforehand. In Sweden, the probability of failure has been prescribed in BKR [5] based on a possible negative outcome since the early 1970s. Structures that are likely to cause harm to man if they collapse must be designed with a maximum annual probability of failure of $10^{-6}$ corresponding to a $\beta$-index of 4.75 . Structures less likely to cause harm to man are allowed to be designed with an annual probability of failure of $10^{-4}$, ( $\beta$-index of 3.72$)$. In normal design, codes with partial coefficients are used to meet these demands. The partial coefficients are applied both on loads and on the bearing capacity and have been calibrated for the proper probability. A partial coefficient can also be used to punish or encourage other important aspects. Favourable factors can be used to encourage the decrease of uncertainties. Durable material, accurate models and good quality control should all be promoted. On the other hand, poorly understood phenomena, brittle failures and poor workmanship should all be punished with unfavourable factors. The load effect, here denoted $S$, and the bearing capacity, here denoted $R$, are both part of the failure function, here denoted $G$. These variables will be further described in the following.

\subsection{Failure function, $G$}

Failure is defined as the load effect being higher then the bearing capacity, which can be described as $G<0$ where $G$ is defined by eqn. (5).

$$
G=R-S
$$

As both load effect, $S$, and bearing capacity, $R$, varies, the probability of failure can be described as the probability of $G$ being less then zero, i.e. $p(G<0)$. After describing the load effect and the bearing capacity, including statistical distributions, the probability of failure can be found. For several failure functions, analytical solutions such as second-order reliability method (SORM) 
described by Thoft-Christensen and Baker [6] can be used with sufficient accuracy. For complicated failure functions or functions that include complicated distributions, it is convenient to use Monte Carlo (MC) simulations. For the calculations in this paper MC simulations have been used even though it would also have been possible to use SORM.

\subsection{Load effect, $S$}

The load effect on a structural component derives from external loads or restrained movements, for example; wind, snow, temperature, dead load, settlements, earthquakes, etc. All these variables causing a load effect are normally stochastic. When strengthening is addressed for an existing structure, it might however be possible to reduce uncertainties on load effect, by studying the real structure including loads by civil structural health monitoring. When strengthening is undertaken with externally bonded fibres, the change of dead load can be neglected. For statically undetermined structures a strengthening can still affect the load effect on a structural member because it will in most cases also change stiffness locally within the structure.

\subsection{Load bearing capacity, $R$}

As described by eqns. (1)-(4), several variables affect the shear bearing capacity of a concrete member. All of these variables are stochastic even though the distribution can be reduced for an existing structure by actually studying each variable on site. By studying the true geometry in several preferably critical areas, uncertainties from construction may be reduced. Actual concrete and steel properties can be tested and the distribution for the true capacities is reduced in accordance with the accuracy of the material testing method. Equations used in models do have their limitations and are related to a specific failure mode. Even for this failure mode, the equations describe the capacity based on assumptions and simplifications. This means that the equations used to describe the bearing capacity have variations in accuracy from structure to structure. This is called model uncertainties and most researchers in the area agree that the uncertainties are larger for models describing shear capacity compared to models for flexural capacity. For a concrete beam strengthened in shear with externally bonded fibres, several different failure modes exist. The failure mode that is described by previous equations is based on fibre rupture, yielding of steel stirrups and a limited crack opening. Other failure modes that can occur are; anchorage failure, concrete strut compression failure and large crack openings that will reduce concrete contribution prior to the ultimate failure. In a probabilistic design all failure modes must be studied and each failure mode can be given a specific probability to occur based on the nature of failure and state-of-the-art knowledge. Furthermore, the mode of failure may change depending on the degree of strengthening. Within a certain range of strengthening and likely distributions of included parameters, the failure mode can, however, be quite reliably described. Partial factors on the load bearing capacity are used to reduce characteristic material strengths, $f_{k}$, to design values, $f_{d}$. Eqn. (6) shows how this reduction may 
be achieved by use of partial coefficients $\gamma_{\mathrm{m}}$ and $\gamma_{\mathrm{n}}$, which describe material uncertainties and the desired safety class respectively.

$$
f_{d}=\frac{f_{k}}{\gamma_{m} \gamma_{n}}
$$

In the Swedish code BKR [5], the coefficient for safety class varies from 1.0 to 1.2 depending on the risk related to a possible collapse. The material coefficient is mainly based on the distribution of the material properties and test method.

\section{Numerical study}

In fig. 1, a cross-section of a reinforced concrete member is shown including externally bonded fibres with some geometrical variables marked. The beam is reinforced with two $16 \mathrm{~mm}$ steel bars in compression and twelve $16 \mathrm{~mm}$ steel bars in compression. The beam has $12 \mathrm{~mm}$ vertical steel stirrups, at $200 \mathrm{~mm}$ spacing, and is strengthened on each side with one layer of unidirectional carbon fibre sheets with a unit weight of $0.2 \mathrm{~kg} / \mathrm{m}^{2}$ placed in vertical direction.

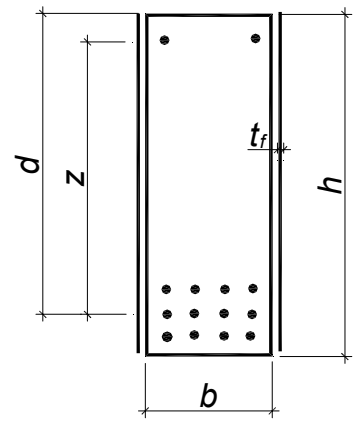

Figure 1: Cross-section of studied beam.

Suggestions for distribution of the variables for reinforced concrete can be found in JCSS PMC, [7], Jeppsson [8] and Plevris et al [9]. For strengthening systems of externally bonded fibres there is a lack of reliable data regarding distributions. Some partial factors for strengthening systems have been suggested by Monti and Santini [4] and Täljsten [11]. In this example, partial factors from the Swedish code, BBK 94 [12] have been used for the safety class and reinforced concrete together with previous equations. For concrete $\gamma_{m}$ is 1.5 , for steel $\gamma_{\mathrm{m}}$ is 1.1 and the highest safety class gives $\gamma_{\mathrm{n}}$ equal to 1.2. In this example, an iterative procedure has been used to determine $\gamma_{\mathrm{m}}$. Based on experience from several tests reported in Carolin and Täljsten [10] on specimens as shown in figure 1, distribution and mean values have been found for the strengthening system. The strengthening of a concrete member was first designed with partial factors and then the probability of failure was determined by setting all variables stochastic. The partial factor for the strengthening system was adjusted until the 
probability of failure for a strengthened structure without steel was the same as for a structure with steel but without strengthening. During this operation deterministic values of the loads, calculated from a bearing capacity based on design values, were used. Then, an evaluation of the probability of failure for a structure with both internal steel and external fibres was carried out with all parameters stochastic. The calculations were made to emphasize and highlight some interesting aspects and to obtain an estimation of a partial factor for the strengthening system. Therefore, no efforts were put into ensuring that the most appropriate distributions were used. All variables with their used distribution, standard deviation where applicable, partial coefficient and design value are reported in table 1 .

Täljsten [11] suggests for externally bonded fibres that $\gamma_{\mathrm{m}}$ is calculated as a product of knock-down factors. These take into account material distribution (i.e. definition of characteristic value), test method contra real value (should be 1 for a good test method), type of failure (i.e. brittle failure w/o bearing capacity is punished), quality control, durability of material, system used (hand lay-up or laminates), and creep behaviour (long or short term loading).

Table 1: $\quad$ Variables used to estimate shear bearing capacity.

\begin{tabular}{|l|c|c|c|c|c|}
\hline Variable & $\begin{array}{c}\text { Mean } \\
\text { value }\end{array}$ & Distribution & $\begin{array}{c}\text { Standard } \\
\text { deviation }\end{array}$ & $\begin{array}{c}\text { Partial } \\
\text { coefficient }\end{array}$ & $\begin{array}{c}\text { Design } \\
\text { value }\end{array}$ \\
\hline $\mathrm{h}$ & $500 \mathrm{~mm}$ & Normal & $5 \mathrm{~mm}$ & 1 & $500 \mathrm{~mm}$ \\
\hline $\mathrm{b}$ & $180 \mathrm{~mm}$ & Normal & $2 \mathrm{~mm}$ & 1 & $180 \mathrm{~mm}$ \\
\hline $\mathrm{d}$ & $\mathrm{h}-80 \mathrm{~mm}$ & - & - & 1 & $420 \mathrm{~mm}$ \\
\hline $\mathrm{A}_{\mathrm{s}}$ & $226 \mathrm{~mm}^{2}$ & Normal & $1 \mathrm{~mm}^{2}$ & 1 & $226 \mathrm{~mm}^{2}$ \\
\hline $\mathrm{s}$ & $300 \mathrm{~mm}$ & Normal & $15 \mathrm{~mm}$ & 1 & $300 \mathrm{~mm}$ \\
\hline $\mathrm{t}_{\mathrm{f}}$ & $0.11 \mathrm{~mm}$ & Deterministic & - & 1 & 0.11 \\
\hline $\mathrm{f}_{\mathrm{v}}$ & $1.8 \mathrm{MPa}$ & Normal & $0.4 \mathrm{MPa}$ & 1.5 & $1.0 \mathrm{MPa}$ \\
\hline $\mathrm{f}_{\mathrm{y}}$ & $515 \mathrm{MPa}$ & Normal & $65 \mathrm{MPa}$ & 1.1 & $390 \mathrm{MPa}$ \\
\hline$\varepsilon_{\mathrm{f}}$ & $10 \% \mathrm{OPa}$ & Normal & $1.5 \%$ o & 1.2 & $6.9 \%$ \\
\hline $\mathrm{E}_{\mathrm{f}}$ & $234 \mathrm{GPa}$ & Normal & $2 \mathrm{GPa}$ & 1 & $230 \mathrm{GPa}$ \\
\hline$\eta$ & 0.67 & Deterministic & - & 1 & 0.67 \\
\hline$\alpha$ & $30^{\circ}$ & Normal & 2 & 1 & $30^{\circ}$ \\
\hline$\beta$ & $90^{\circ}$ & Normal & 3 & 1 & $90^{\circ}$ \\
\hline$\theta$ & $\alpha+\beta-90^{\circ}$ & - & - & 1 & $30^{\circ}$ \\
\hline $\mathrm{S}\left(\mathrm{V}_{\mathrm{c}}\right)$ & $75.6 \mathrm{kN}$ & Deterministic & - & 1 & $75.6 \mathrm{kN}$ \\
\hline $\mathrm{S}\left(\mathrm{V}_{\mathrm{c}}+\mathrm{V}_{\mathrm{s}}\right)$ & $187 \mathrm{kN}$ & Deterministic & - & 1 & $187 \mathrm{kN}$ \\
\hline $\mathrm{S}\left(\mathrm{V}_{\mathrm{c}}+\mathrm{V}_{\mathrm{f}}\right)$ & $177 \mathrm{kN}$ & Deterministic & - & 1 & $177 \mathrm{kN}$ \\
\hline $\mathrm{S}\left(\mathrm{V}_{\mathrm{c}}+\mathrm{V}_{\mathrm{s}}+\mathrm{V}_{\mathrm{f}}\right)$ & $289 \mathrm{kN}$ & Deterministic & - & 1 & $289 \mathrm{kN}$ \\
\hline & & & & & \\
\hline
\end{tabular}

\section{Results and analysis}

The failure function presented above was subjected to the Monte Carlo analysis. The probability of failure converged for each case for less then 100000 
simulations. By the used procedure, a partial factor $\gamma_{\mathrm{m}}$ of 1.2 was found for the fibres when externally bonded to concrete. In table 2 probabilities for failure as a result of 100000 simulations are reported.

Table 2: $\quad$ Probability of failure.

\begin{tabular}{|l|c|}
\hline & $\mathrm{p}_{\mathrm{f}}(\mathrm{G}<0)$ \\
\hline$G=R\left(V_{c}\right)-S\left(V_{c}\right)$ & 0.0295 \\
\hline$G=R\left(V_{c}+V_{s}\right)-S\left(V_{c}+V_{s}\right)$ & 0.018 \\
\hline$G=R\left(V_{c}+V_{f}\right)-S\left(V_{c}+V_{f}\right)$ & 0.008 \\
\hline$G=R\left(V_{c}+V_{s}+V_{f}\right)-S\left(V_{c}+V_{s}+V_{f}\right)$ & 0.00057 \\
\hline
\end{tabular}

The reported probabilities for failure in table 2 are high. This is based on applied loads that were chosen as deterministic values instead of being the upper characteristic percentile as used in design. If the load had been chosen stochastically with a proper mean value and distribution, the failures would have been lower. The reason for not using a stochastic load is that it would have introduced uncertainties on distributions for the loads that are dependent on the reason for strengthening. Table 2 shows that in relation to a non-reinforced concrete member the probability of failure for a steel reinforced member is 0.61 $(0.018 / 0.0295=0.61)$, i.e. $1.6(1 / 0.61)$ times safer. In the same way the probability of failure for a fibre strengthened concrete beam is only 0.27 of the probability of the concrete beam, i.e. 3.7 times safer. With the small probabilities that are studied, the probabilities of failure are in the same range. The probability of failure when both steel and fibres are contributing to the capacity is lower then the others, i.e. 0.019 of the probability of the concrete beam that equals 53 times safer. The reason why the safety increases with both steel reinforcement and fibre strengthening is that it is necessary that all variables be at critical values at the same time for failure to occur. Weak fibres can be compensated by steel bars having mean values and the structure will have a bearing capacity larger than the load effect. In the same way, fibres with a medium performance can compensate for steel bars that have a performance lower than its 5\% -fractal. The probability for both materials, and therefore the load bearing capacity to be lower than the minimum acceptable level for the strengthened structure, will decrease compared to the non-strengthened structure even though the load effect has increased. The same results have been found in previous work by Carolin [13] when strengthening for flexure was studied.

\section{Discussion and conclusions}

It is possible to find appropriate partial coefficients so that the probability for failure will be similar for the original structure subjected to original loading and the strengthened structure with the higher loading. Different amounts of strengthening will however give different importance to the different stochastic variables and implies that the partial coefficient in such a case would vary with 
the strengthening amount. The strengthening ratio is obviously not known when design is undertaken and in the case of a small amount or no internal steel, CFRP provides safety. It is not reasonable with variation of the partial coefficient and it is suggested that coefficients are determined as if the variables for the existing structure were deterministic. This approach will give an additional reliability of the structure that should be seen as an extra safety provided by the strengthening system. A partial coefficient determined in the suggested way would also be eligible to use design in cases when real parameters of the existing structure have been measured to reduce uncertainties and their partial factors. When calibrating partial coefficient and making comparisons with traditional structures, one should keep in mind that models for contribution to bearing capacity from strengthening systems are often based on strains that are multiplied with stiffness. Traditional design however is often based on stresses. This gives that the distribution of material parameters on stiffness and strain should only be applied on one or the other, especially since theses parameters might be highly correlated. This also gives a possibility of using different factors for design in the service limit state, SLS, and the ultimate limit state, ULS. It is suggested that partial factors for design in the ULS are applied on strain, and partial factors are applied on stiffness for design in the SLS.

For a beneficial sense of safety, structures should be designed to fail with adequate warning signals preceding a potential collapse. Failures that might be seen as brittle and therefore should be avoided are; fibre rupture, shear and anchorage failures. By seeing risk as the combination of probability and consequence, brittle failures with no warnings may give larger consequences and should therefore have a lower probability of occurring to keep the risk at a constant level. As suggested by Pilakoutas et al [14], undesired failures should be designed to be less probable. One way could be to use different partial factors for different failure modes. For instance, a higher partial factor for the design of anchorage could be used and in designing for shear, an increased partial factor on shear loads can be applied. In light of avoiding less desired failure modes, it is not a disadvantage that shear models are less accurate than models describing flexural capacity. With the same probability of failure, a less accurate model will have a wider distribution thus the average value of bearing capacity will be higher compared to a more accurate model. Hence, if designed for the same probability of failure, a flexural failure is more likely to occur than a shear failure. When studying structural safety and strengthening, a possible loss of strengthening effect, from for example vandalism or fire, must also be considered. For such cases when studying the bearing capacity and probability of failure it is necessary to also evaluate the likeliness of loads under such circumstances.

Probabilistic design requires knowledge of used materials. When it comes to high performing fibres there is a lack of product standards for civil engineering purposes. For civil engineering, properties are reported for the fibres and it does not seem to be lower percentiles. When performing a coupon test, one can find that the strain capacity of a coupon is lower compared to the rupture strain of the pure fibres. It has also been found that when fibres are bonded to a structure the 
capacity decreases even further. With this in mind, there is a need for proper data on the fibre material when bonded to concrete structures. The presented work could be summarized into a few points; for uniform treatment of risk and safety, the probabilistic approach should be used for the design of strengthening; strengthening provides high safety to existing structures; probabilistic design is a powerful tool to control the probability of failure modes, favor can be given to models providing good accuracy; and data on properties for used materials are needed.

\section{References}

[1] EN, Eurocode - Basis of structural design. EN 1990:2002 (E), CEN, European Committee for Standardization, Brussels, 87 pp. 2002

[2] Carolin, A., Carbon Fibre Reinforced Polymers for Strengthening of Structural Elements, Doctoral Thesis, Luleå University of Technology, 184 pp. http://epubl.luth.se/1402-1544/2003/18. 2003

[3] Carolin, A. \& Täljsten, B., Theoretical study on strengthening for increased shear bearing capacity. Journal of Composites for Construction 9(6) pp 497-506. 2005

[4] Monti, G. \& Santini, S., Reliability-based Calibration of Partial Coefficients for Fiber-Reinforced Plastic. Journal of Composites for Construction. August. pp 162-167, 2002

[5] BKR 94, Konstruktionsregler. Norstedts tryckeri, Stockholm, 176 pp, (in Swedish), 1994

[6] Thoft-Christensen, P. \& Baker, M.J., Structural Reliability Theory and its Application, Springer-Verlag, Berlin Haidelberg, New York, 1982.

[7] JCSS PMC, Probabilistic Model Code. Joint Committee on Structural Safety, JCSS, http:/www.jcss.ethz.ch/JCSSPublications/PMC/PMC.html.

[8] Jeppsson, J., Reliability-Based Assessment Procedure for Existing Concrete Structures, Doctoral Thesis, Lund University of Technology, 188 pp, 2003

[9] Plevris, N., Triantafillou, T. \& Veneziano, D., Reliability of RC Members Strengthened with CFRP Laminates, Journal of Structural engineering. July, pp. 1037-1044, 1995

[10] Carolin, A. \& Täljsten, B., Experimental study on strengthening for increased shear bearing capacity. Journal of Composites for Construction 9(6) pp 488-496. 2005

[11] Täljsten, B., FRP Strengthening of Existing Concrete Structures - Design Guidelines - Second Edition, Luleå University of Technology, 230 pp, 2003

[12] BBK 94, Boverkets handbok om betongkonstruktioner, BBK 94, Band 1, Konstruktion,. Boverket, Stockholm, 185 pp, (in Swedish), 1995

[13] Carolin, A., Probabilistic design of frp strengthening of concrete structures, Proc. of $3^{\text {rd }}$ Int. Conf. on FRP Composites in Civil Engineering pp 243-246. 2006

[14] Pilakoutas, K., Neocleous, K. \& Guadagnini, M., Design Philosophy Issue of Fiber Reinforced Polymer Reinforced Concrete Structures, Journal of composites for construction. August, pp. 154-161, 2002 